\title{
Tar and Particulate Removal Methods for the Producer Gas Obtained from Biomass Gasification
}

\author{
R. Preetha Devi ${ }^{1 *}$, S. Kamaraj ${ }^{1}$, R. Angeeswaran ${ }^{2}$ and S. Pugalendhi ${ }^{1}$ \\ ${ }^{1}$ Department of Bioenergy, AEC \& RI, TNAU, Coimbatore-03, T.N., India \\ ${ }^{2}$ International Institute of Renewable Energy, NERD Society, Vadavalli, Coimbatore, T.N., India \\ *Corresponding author
}

\section{A B S T R A C T}

\begin{tabular}{|l|l|l|l|l|l}
\hline Keywords & $\begin{array}{l}\text { Alternative energy production through biomass gasification produces } \\
\text { combustible gases, such as carbon monoxide, hydrogen, and methane. } \\
\text { Biomass } \\
\text { gasification, } \\
\text { Limitation. }\end{array}$ & $\begin{array}{l}\text { These gases can be used for generation of direct heat, electricity, or liquid } \\
\text { fuels through the Fischer Tropsch process. However, a major limitation of } \\
\text { the overall process is the purity of the generated synthesis gas. The tars and } \\
\text { particulates generated in the gasification process constitute a major } \\
\text { Article Info }\end{array}$ \\
$\begin{array}{l}\text { Accepted: } \\
\text { 04 September } 2017 \\
\begin{array}{l}\text { Available Online: } \\
\text { 10 October } 2017\end{array}\end{array}$ & $\begin{array}{l}\text { condense on valves, fittings, and therefore, hinder the smooth running of an } \\
\text { engine. }\end{array}$
\end{tabular}

\section{Introduction}

The gasification of carbon-containing materials to produce combustible gas is an established technology. Coal gasification has been the primary focus due to its higher energy density and ease of transportation in comparison to renewable biomass resources. Currently, environmental issues and the need to augment or replace existing power generation facilities have shifted the focus of gasification development from non-renewable fossil fuel sources to renewable fuel sources, mainly biomass.

\section{Biomass}

The term "biomass" represents material of biological origin derived from plants as a result of the photosynthetic conversion process excluding materials embedded in geological formations and transformed to fossil. In principle, biomass is a less damaging and environmentally benign fuel as the carbon dioxide released from the combustion process is captured during the plant growth. One of the most important biomass fuels is wood, however, wood is often too valuable to be used for power generation and the timber industry is able to make better use of trees by processing them into construction materials. Therefore, residues such as bark, sawdust, and odd-sized pieces are frequently used as fuel. Many agricultural residues can, indeed, be used as fuels. They include straw from grains, husks 
from rice, coconuts or coffee, stalks from maize or cotton, bagasse from sugarcane, and animal manure. In addition to these, dedicated energy crops such as switch grass are being used as fuel sources. Using these biomass residues as fuels may solve the environmental problem of how to dispose of them.

\section{Biomass gasification}

Biomass gasification is a thermochemical process that produces relatively clean and combustible gases through pyrolytic reaction. The synthesis gas (also known as syngas or producer gas) generated can be an important resource suitable for direct combustion, application in prime movers such as engines and turbines, or for the production of synthetic natural gas (SNG) and transportation fuels (e.g. Fischer-Tropsch diesel). Producing high quality syngas to meet operational requirements of turbines or internal combustion engines is critical to the successful implementation of biomass gasification. Specifically, the efficient and economic removal of tars and particulates from the syngas are the major obstacles to be overcome (Table 3 ).

For energy production, the major concerns about syngas are its heating value, composition, and possible contamination. The proportion of the combustible gases hydrogen $\left(\mathrm{H}_{2}\right)$, methane $\left(\mathrm{CH}_{4}\right)$, carbon monoxide $(\mathrm{CO})$ and steam in the syngas determines the heating value of the gas. The composition of syngas depends on the biomass properties and gasifier operating conditions. For a particular gasification system, operating conditions play a vital role in all aspects of biomass gasification. These include carbon conversion, syngas composition, tar formation and reduction. Syngas from biomass gasification contains tar and particulates as impurities which can cause severe operational problems.

\section{Tar}

The organics, produced under thermal or partial-oxidation regimes (gasification) of any organic materials are called "tars". Tar includes the variety of oxygenated aromatics formed in the pyrolysis step of the gasification process. Molecular weight of the tar is greater than the Benzene (molecular weight of benzene is 78). The actual composition of tar is complex, it dependent on the severity of the reaction condition, including gasifier temperature and reaction time in the reactor. The biomass feedstock is heated, it dehydrates and then volatilizes as it thermally decomposes. The volatilized material either can undergo further decomposition to form permanent gases, or it can undergo dehydration, condensation and polymerization reactions that result in tar formation.

Tar is undesirable because of various problems associated with condensation, formation of tar aerosols and polymerization to form more complex structures, which can damage internal combustion engines (ICEs), gas turbines, hot gas application and other machinery. Therefore, before the syngas can be used in a gas engine or turbine, it must be cleaned of impurities, especially tars, a major impediment to widespread use of biomass gasification technology. Currently, there is no specific method for determining the concentration of tar and particulates from biomass gasification. Developing a simple and effective protocol for quantifying the gravimetric tar and particulate in biomass gasification is an important goal of this study. Gas cleaning and tar reduction have been the subject of research on thermochemical conversion of biomass for the production of energy and chemicals. Catalytic tar destruction for coal gasification has been studied for several decades and a number of reviews have been written on biomass 
gasification hot gas cleanup emphasizing the use of dolomites and nickel based catalyst (Stevens, (2001); Sutton et al., (2001); Milne et al., (1998)). Physical treatment of syngas using mechanical methods such as cyclone, scrubber, and particulate filters has also been identified (Devi et al., 2003). This study will also look at the effects of temperature on the performance of physical methods and chemical proprietary catalysts for tar removal in an industry.

\section{Biomass as a fuel}

Biomass simply refers to organic materials originated from plants (wood, crops etc.) and animal wastes. Different biomass conversion processes produce heat, electricity and fuels. Among all biomass conversion processes, gasification is one of the most promising (Devi et al., 2003). An assessment of the use of biomass as a fuel requires a basic understanding of their composition, characteristics, and performance. Each type of biomass has specific properties that determine its performance as a fuel in combustion or gasification devices or both (Quaak et al., 1999). The most important properties relating to the thermal conversion of biomass are moisture content, ash content, volatile matter, and energy density. In addition to high temperature gasification, biomass can be used to produce energy via low temperature microbial gasification process where methane is mainly produced anaerobically.

\section{Moisture content}

This is the amount of water in the material, expressed as a percentage of the material's weight. This weight can be on a wet basis, on a dry basis, and on a dry-and-ash basis. Biomass materials exhibit a wide range of moisture content and since this affects its value as a fuel source, it is important that the basis be stated whenever moisture content is measured. If the moisture content is excessive, the combustion process may not be self-sustaining and supplemental fuel must be used, which could defeat the objective of producing energy by biomass combustion for captive use or market (Klass, 1998).

\section{Ash \#ontent}

This refers to the inorganic component in biomass. It is expressed in the same format as the moisture content. This property is especially important under high temperature gasification as melted ash may cause problems in the reactor (Quaak et al., 1999).

\section{Elemental composition}

The ash-free organic components of biomass are relatively uniform. The major components are carbon, oxygen, and hydrogen. Most biomass may also contain a small amount of nitrogen.

\section{Volatile matter content}

The part of the biomass that is released when the biomass is heated is referred to as the volatile matter. Biomass feedstock contains a very high proportion of volatile organic material, 70 to $90 \%$ for wood (Klass, 1998).

\section{Energy density}

The energy density refers to the potential energy available per unit volume of the biomass. It is dependent on the feedstock heating value and bulk density. In general, the biomass energy density of biomass is about one-tenth of that of fossil fuels.

\section{Biomass gasification principle}

The chemistry of biomass gasification is similar to that of coal gasification in the sense that thermal decomposition of both solids occurs to yield a mixture of essentially the same gases. However, biomass gasification 
occurs under much less severe operating conditions than for coal feedstock because its main constituents, the high-oxygen cellulosics and hemicellulosics, have higher reactivity than the oxygen-deficient, carbonaceous materials in coal. The thermo-chemical processes involved in gasification are drying, pyrolysis, oxidation, and reduction.

\section{Drying}

This phase involves evaporation of the moisture contained in the biomass. At temperatures above $100^{\circ} \mathrm{C}$, water in the biofuel is converted to steam. Part of this vapor may be reduced to hydrogen during gasification and the rest ends up as moisture in the produced syngas.

\section{Pyrolysis}

The bio-fuels begin to pyrolyze at temperatures above $200^{\circ} \mathrm{C}$ (Klass, 1998). This is the thermal decomposition of the fuel into volatile gases and char. The proportion of these components is influenced by the chemical compositions of bio-fuels being fed and the operating conditions of the gasifier. The main process of thermal decomposition of biomass can be represented as follows:

$\mathrm{C}_{6} \mathrm{H}_{10} \mathrm{O}_{5}+\mathrm{Heat} \rightarrow \mathrm{yCxHz}+\mathrm{qCxHnOk}+\mathrm{CO}$ $+\mathrm{C}$

\section{Oxidation}

After pyrolysis, there is an oxidation zone where the pyrolysis products move into the hotterzones of the gasifier. Air is introduced into the oxidation zone under starved oxygen conditions. The oxidation takes place at temperatures ranging from 700$1000^{\circ}$ Coxidation reactions is as follows (Klass, 1998)

$\mathrm{C}+\mathrm{O}_{2} \rightarrow \mathrm{CO}_{2}+$ Heat

$\mathrm{H}_{2}+1 / 2 \mathrm{O}_{2} \rightarrow \mathrm{H}_{2} \mathrm{O}+$ Heat
$\mathrm{CO}+1 / 2 \mathrm{O}_{2} \rightarrow \mathrm{CO}_{2}+$ Heat

$\mathrm{CH}_{4}+3 / 2 \mathrm{O}_{2} \rightarrow \mathrm{CO}+2 \mathrm{H}_{2} \mathrm{O}$

\section{Reduction}

The reaction products of the oxidation zone continually move into the reduction zone where there is insufficient oxygen, leading to reduction reactions between the hot gases and char. The principal reactions are as follows.

$$
\begin{array}{ll}
\mathrm{CO}_{2}+\mathrm{C}+\text { Heat } & \rightarrow 2 \mathrm{CO} \\
\mathrm{C}+\mathrm{H}_{2} \mathrm{O}+\text { Heat } & \rightarrow \mathrm{CO}+\mathrm{H}_{2} \\
\mathrm{CO}+\mathrm{H}_{2} \mathrm{O}+\text { Heat } & \rightarrow \mathrm{CO}+\mathrm{H}_{2}
\end{array}
$$

In this zone, the sensible heat of the gases and char is converted into the stored chemical energy in the syngas. Therefore, the temperature of the gases is reduced during this process.

\section{Gasification systems}

Gasification is a form of incomplete combustion; heat from the burning solid fuel creates gases which are unable to burn completely, due to insufficient amounts of oxygen from the available supply of air. By weight, syngas from gasification of wood contains approximately $15-21 \%$ hydrogen $\left(\mathrm{H}_{2}\right), 10-20 \%$ carbon monoxide (CO), $11-13 \%$ carbon dioxide $\left(\mathrm{CO}_{2}\right)$, and $1-5 \%$ of methane, all of which are combustible plus nitrogen $\left(\mathrm{N}_{2}\right)$. The nitrogen is not combustible; however, it does occupy volume and dilutes the syngas as it enters and burns in an engine. A generalized reaction describing biomass gasification is as follows (Dayton, 2002):

Biomass + air $\left(\right.$ or $\left.\mathrm{H}_{2} \mathrm{O}\right) \rightarrow \mathrm{CO}, \mathrm{CO}_{2}, \mathrm{H}_{2} \mathrm{O}, \mathrm{H}_{2}$, $\mathrm{CH}_{4}$, and $\mathrm{N}+$ tars + particulates

The actual biomass syngas composition depends on the gasification process, the gasifying agent, and the feedstock composition. Various gasification 
technologies have been under investigation for converting biomass into a gaseous fuel. A characteristic of the various gasifiers is the way in which the fuel is brought into contact at the gasification stage. Four types of reactors exist:

Updraft or counter current gasifiers

Downdraft or co-current gasifiers

Cross-draft gasifiers and

Fluidized-bed gasifiers

\section{Fixed bed gasifiers}

Fixed bed gasifiers have grates built in to support the feedstock and maintain a stationary reaction bed. They are relatively easy to design and operate but have limited capacity. Therefore, fixed bed gasifiers are preferred for small to medium scale applications with thermal requirements up to $1 \mathrm{MW}$ (Klein, 2002). Fixed bed gasifiers can be classified as either updraft or downdraft depending on the method of air introduction.

\section{Updraft or countercurrent gasifiers}

In this type of reactor, air is taken in at the bottom, and the gas leaves at the top. The biomass moves counter to the gas flow and passes successively through drying, pyrolization, reduction, and hearth zones. In the drying zone, the biomass is dried. In the pyrolization zone, it is decomposed into volatile gases and solid char. The heat for pyrolization is mainly delivered by the upward-flowing producer gas and partly by radiation from the hearth zone. The advantages of this type of gasifier are its simplicity, relatively low gas-exit temperature, high thermal efficiency and as a result, biomass with high moisture content (up to $60 \% \mathrm{wb}$ ) (Quaak et al., 1999) can be gasified without any pre-drying of the feed. Moreover, size specifications are not very critical for this gasifier. Major drawbacks are the high amounts of tar produced.

\section{Downdraft or co-current gasifiers}

In the downdraft gasifier, air is introduced into downward flowing packed bed or solid fuels and gas is drawn off at the bottom. The zones are similar to those in the updraft gasifier; but the order is somewhat different (Quaak et al., 1999). A lower overall efficiency and difficulties in handling higher moisture and ash content are common problems in small downdraft gas producers. In addition to these drawbacks, it is important for downdraft gasifiers to maintain uniform high temperatures over a given cross-sectional area in the reaction chamber. These factors limit the use of downdraft gasifiers to a power range of less than $1 \mathrm{MW}$. This gasifier is, however, preferred to updraft gasifier for internal combustion engines because of the low tar content associated with the syngas.

\section{Fluidized-bed gasifiers}

Fluidized-bed gasification was initially developed to overcome operational problems of fixed-bed gasification of fuels with high ash content, but is suitable for large capacities (more than 10MW) in general. The fuel is fed into a suspended (bubbling fluidized-bed) or circulating (circulating fluidized-bed) hot sand bed. The bed behaves like a fluid and is characterized by high turbulence. Fuel particles mix quickly with the bed material, resulting in rapid pyrolysis and a relatively large amount of gases. Major problems with fluidized bed gasification are the resulting high tar content (up to $500 \mathrm{mg} / \mathrm{Nm}^{3}$ ), incomplete carbon combustion, and poor response to load changes. Problems with feeding, instability of the reaction bed, and fly-ash sintering in the gas channels can occur with some bio-fuels. There are two principal types of fluidized bed gasifiers namely, bubbling fluidized bed (BFB) and circulating 
fluidized bed (CFB). The circulating type separates and recycles fly-ash from the reaction bed while the bubbling type does not. Fluidized bed gasifiers have been the focus of appreciable research and development for large scale generation (Klein, 2002; and Spliethoff, 2001) (Table 1).

\section{Gas quality requirements}

The product gas formed from biomass gasification contains both combustible and noncombustible components. The combustible gases include $\mathrm{CH}_{4}, \mathrm{CO}$ and $\mathrm{H}_{2}$. The major noncombustible components are $\mathrm{CO}_{2}, \mathrm{H}_{2} \mathrm{O}$ and $\mathrm{N}_{2}$, in addition to organic (tars) and inorganic impurities (Alkali metals, $\mathrm{H}_{2} \mathrm{~S}$, $\mathrm{HCl}, \mathrm{NH}_{3}$ ), and particulates. The generation of $\mathrm{H}_{2} \mathrm{~S}$ is of little importance in biomass gasification as long as the biomass contains less than $0.5 \%$ sulfur content. $\mathrm{NH}_{3}$ is dependent on the nitrogen content of the biomass and biomass with less than $2 \%$ nitrogen is safe for gasification (Table 2).

In gasification, tar is defined as a mixture of organic compounds in the product stream that are condensable in the gasifier or in downstream processing steps or conversion devices (Milne et al., 1998). The gas quality indicates the extent to which the gas is suitable for end use equipment or process and is represented by several parameters including chemical composition, tar and particulate concentration, and Lower Heating Value (LHV) and is dependent upon the requirements of the end use itself. The gas quality for power generation is tabulated below.

\section{Gas conditioning}

Before the producer gas can be used in a gas engine or turbine, it must be cooled and cleaned of tars, alkali metals, and dust. Basically, there are two main options for controlling the tar content in gasifier product gas depending on where tar is removed; either in the gasifier itself (primary measures) or outside the gasifier (secondary measures) (Devi et al., 2003).

\section{Primary methods}

This can be achieved by optimizing biomass fuel properties and/or gasifier design and operating conditions. An ideal primary method concept eliminates the use of secondary treatments. The primary measures include: proper selection of the operating conditions, the use of catalysts during gasification, and proper gasifier design (Devi et al., 2003).

\section{Temperature}

Biomass gasification is carried out at relatively high temperatures (above 800). Increasing the temperature in the gasification of sawdust in a fixed bed gasifier produces a decrease in the total number of detectable tar species (Kinoshita et al., 1994).

\section{Pressure}

Pressurized and atmospheric gasifiers are currently used in advanced biomass gasification designs. Experiments involving gasification of Wisconsin whole tree chips indicated that when pressure was increased to 21.4 bar, the amount of total tar decreased (Knight, 2000).

\section{Gasifying medium}

Air, steam, steam-oxygen mixture and carbon dioxide have been used as gasifying media. Heating value of the producer gas with air as the gasifying is lower because of the high percentage of nitrogen produced. Steam gasification produces a gas with a lower percentage of nitrogen and a higher 
percentage of hydrogen. However, steam gasification is endothermic and hence sometimes requires complex design for heat supply in the process (Devi et al., 2003).

\section{Equivalence Ratio (ER)}

Equivalence ratio can be defined as the ratio of the actual air fuel ratio to the air fuel ratio needed for complete combustion. This is an important factor in biomass gasification using air as gasifying medium. Tar yield decreases as ER increases because of more availability of oxygen to react with volatiles in the flaming pyrolysis zone. However, a higher ER value tends to favor high carbon dioxide content in the producer gas at the expense of hydrogen and carbon monoxide, and therefore a lower heating value.

\section{Catalysts}

The use of catalysts during biomass gasification affects the producer gas composition and reduces the tar yield. Three group of catalyst materials have been applied in biomass gasification systems-alkali metals, non-metallic oxides, and supported metallic oxides. Alkali metals are considered as primary catalysts. They enhance char formation reactions during thermo-chemical conversion.

\section{Gasifier design}

A two-stage gasifier has been studied in the stage gasifier (Figure 1) (Devi et al., 2003), tars formed during pyrolysis (first stage) are decomposed in the reduction zone (second stage). The Technical University of Denmark also designed a two-stage gasifier (Figure 2) where a combination of pyrolysis of the biomass feed with subsequent partial oxidation of the volatile products in the presence of a charcoal bed was achieved. The modifications made in the gasifier design should be able to produce a gas of high heating value with low tar content, and it should be economically feasible.

\section{Secondary methods}

This is achieved by applying downstream cleaning processes. These methods can be physical or chemical and include the following:

The use of cyclone, baffle filter, ceramic filter, fabric filter, rotating particle separator, electrostatic filter and/or scrubbers. These are normally placed external to the gasifier.

Tar cracking downstream the gasifier either thermally or catalytically. Although, these methods are reported to be very effective in tar reduction, in some cases they are not economically viable (Devi et al., 2003). Figure 3 illustrates the secondary method of gas cleaning and conditioning.

\section{Cyclone}

The Cyclone is the most widely used technique to separate the Syngas from the dust and ash entrained in the gas stream. The basic principle behind cyclone separators is to use centrifugal force to make it possible to separate dust particles from a gas stream (Fig. 4). A cone section causes the vortex diameter to decrease until the gas reverses on itself and spins up the center to the outlet pipe or vortex finder. The shape of the cone induces the stream to spin, creating a vortex. Larger or denser particles are forced outward to the walls of the cyclone where the drag of the spinning air as well as the force of gravity causes them to fall down the sides of the cone into an outlet (Seinfeld, 1975; Svarovsky, 1984). The separation efficiency of a cyclone is usually expressed as the particle size that will be separated with $50 \%$ efficiency (Fredriksson, 1999).

Particulate filters 
To separate particles from a flowing gas, some type of filter may be used. A filter has two important characteristics: its efficiency and resource consumption. The efficiency is quantified as the fraction of incoming particles which are retained by the filter. The efficiency of a filter depends on many parameters, of which the particle size is often the most important. The resource consumption can be divided into initial costs and costs of operation (e.g. pressure drop and use of materials) as well as maintenance costs. The pressure drop often depends on the resource consumption can be divided into initial costs and costs of operation (e.g. pressure drop and use of materials) as well as maintenance costs. The pressure drop often depends on the accumulated amount of particles, and may well define the practical capacity of the filter.

Filter media are materials which collect particles from a contaminated gas passing through. Bag-filters, cartridge filters and granular filters belong to this category. Filter materials may be of the surface collection type (e.g. Gore-TEX and Tetra-TEX membranes) or depth collection type (glass fibers and granular filters) (Hindsgaul, 2000). The particles are collected on the fibers by interception and diffusion. Interception is when a particle hits a fiber due to inertia effects or because the particle is large enough to touch the fiber as it passes. Interception is the most important effect for larger particles $(>1 \mu \mathrm{m})$ (Hindsgaul, 2000). Diffusionis when the Brownian motions of the particle bring it in contact with the filter material. Diffusion is the major collection effect for submicron particles $(<1 \mu \mathrm{m}) \quad$ (Hindsgaul, 2000). Hindsgaul, 2000 identified two common types of filters namely, baghouse and cartridge filters.

Table.1 Typical characteristics of fixed-bed and fluidized-bed gasifiers

\begin{tabular}{|l|l|l|}
\hline \multicolumn{1}{|c|}{ Characteristic } & \multicolumn{1}{|c|}{ Fixed-bed downdraft } & Fluidized-bed \\
\hline Fuel: size $(\mathrm{mm})$ & $10-100$ & $0-20$ \\
Ash content $(\% \mathrm{wt})$ & $<6$ & $<25$ \\
Operating temperature $\left({ }^{\circ} \mathrm{C}\right)$ & $800-1400$ & $750-950$ \\
Control & Simple & Average \\
Turndown ratio & 4 & 3 \\
Capacity $(\mathrm{MW})$ & $<2.5$ & $1-50$ \\
Tar content $\left(\mathrm{g} / \mathrm{m}^{3}\right)$ & $<3$ & $<5$ \\
LHV $\left(\mathrm{MJ} / \mathrm{m}^{3}\right)$ & 4.5 & 5.1 \\
\hline
\end{tabular}

Table.2 Gas quality requirements for power generators

\begin{tabular}{|l|l|l|l|}
\hline \multicolumn{1}{|c|}{ Parameter } & \multicolumn{1}{|c|}{ Unit } & \multicolumn{1}{c|}{ IC engine } & \multicolumn{1}{c|}{ Gas turbine } \\
\hline Particles & $\mathrm{mg} / \mathrm{Nm}^{3}$ & $<50$ & $<30$ \\
Particle size & $\mu \mathrm{m}$ & $<10$ & $<5$ \\
Tar & $\mathrm{mg} / \mathrm{Nm}^{3}$ & $<100$ & N/A \\
Alkali metals & $\mathrm{mg} / \mathrm{Nm}^{3}$ & N/A & 0.24 \\
\hline
\end{tabular}

Table.3 Reduction of tars and particulates in various producer gas cleaning systems 


\begin{tabular}{|c|c|c|c|}
\hline Techniques & Temperature & Particles reduction (\%) & Tars reduction (\%) \\
\hline Sand bed filter & $10-20$ & $70-99$ & $50-97$ \\
Wash tower & $50-60$ & $0-98$ & $10-25$ \\
Venturi scrubber & $\mathrm{n} / \mathrm{a}$ & $\mathrm{n} / \mathrm{a}$ & $50-90$ \\
Rotational atomizer & $<100$ & $95-99$ & $\mathrm{n} / \mathrm{a}$ \\
Wet electrostatic & $40-50$ & $>99$ & $0-60$ \\
Precipitator & 130 & $70-95$ & $0-50$ \\
Fabric filter & 130 & $85-90$ & $30-70$ \\
Rotational particle & & & \\
separator & 80 & $\mathrm{n} / \mathrm{a}$ & 50 \\
Fixed bed tar adsorber & 900 & $\mathrm{n} / \mathrm{a}$ & $>95$ \\
Catalytic tar cracker & &
\end{tabular}

Fig.1 Two-stage gasifier concept

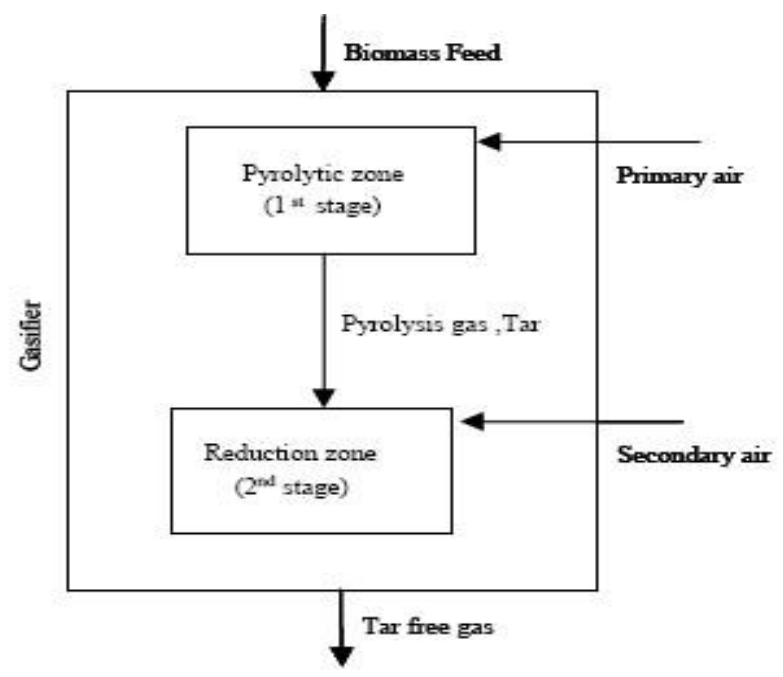

Fig.2 Two-stage gasifier (Devi et al., 2003)

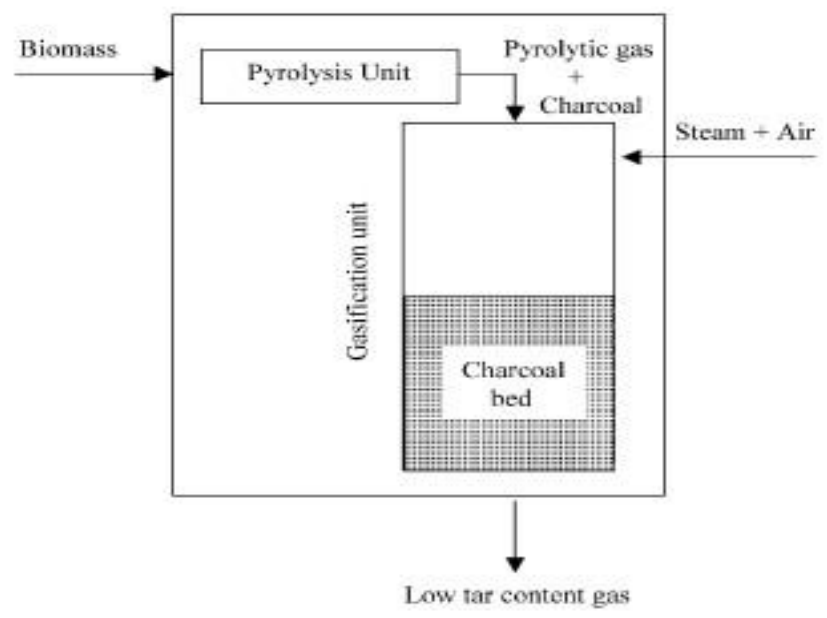

Fig.3 Tars reduction by secondary methods 


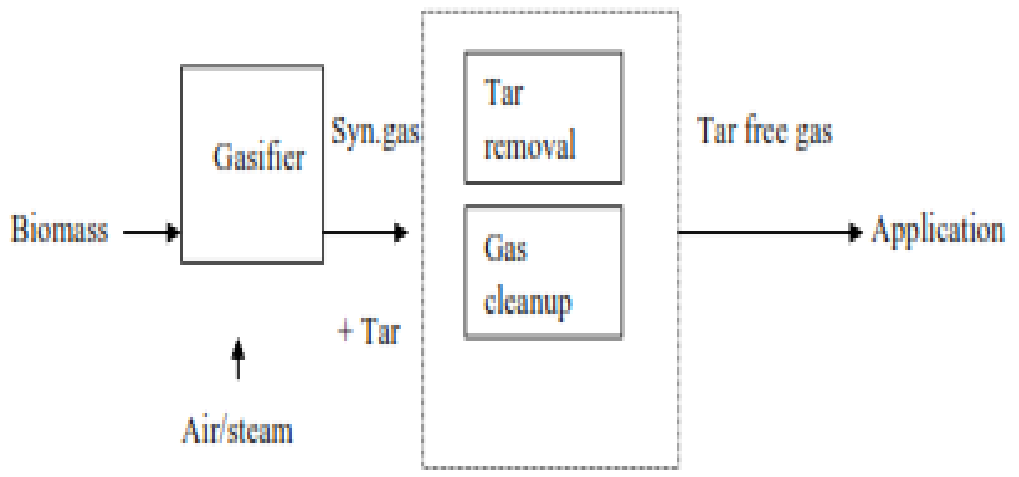

Fig.4 Cyclone separator (Global Air Filtration Systems Inc.)

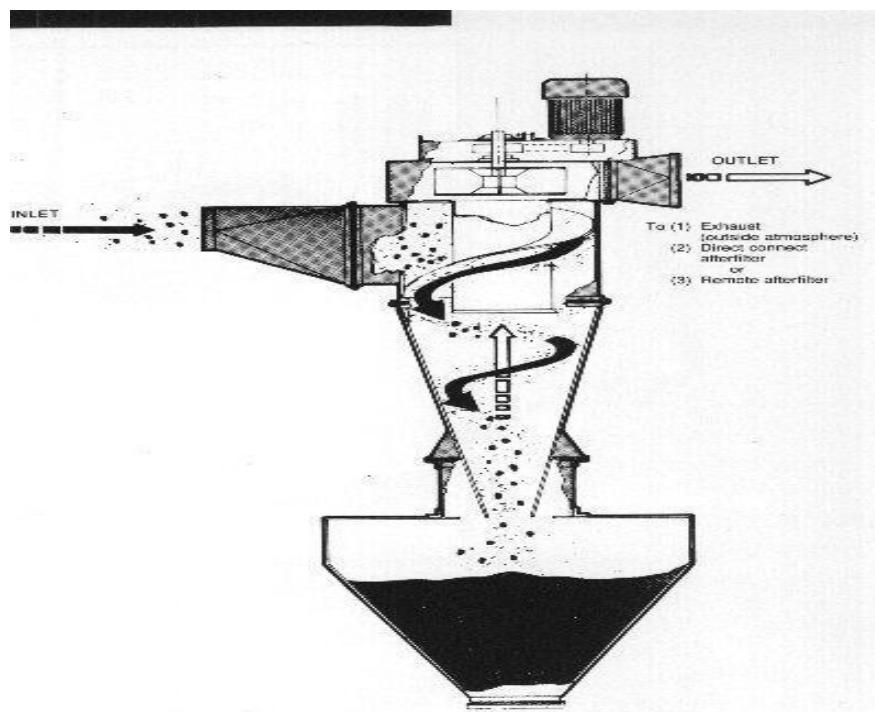

Fig.5 Baghouse filters

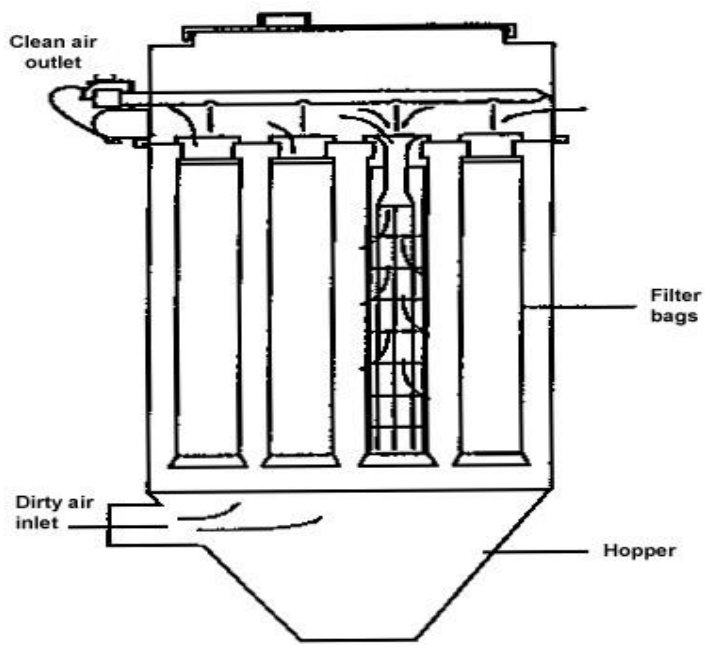

Baghouse filters 
In baghouse collectors, the dust filled air stream passes through fabric bags that filter the dust particles. Bags are made of different material such as woven or felted cotton, synthetic, or glass-fiber and the choice of one over the other may depend on the temperature of the raw gas. Figure 5 shows a baghouse filter arrangement. An advantage of this setup is the ability to do maintenance on one filter while in operation.

\section{Cartridge filters}

Cartridge filter can be surface or depth-type filter. Depth-type filters capture particles and contaminant through the total thickness of the medium, while in surface filters (usually made of thin materials like papers, woven wire, and cloths) particles are blocked on the surface of the filter. The membrane and fibrous type of filters have been used for gasification (Hindsgaul, 2000). It can be generally stated that if the size of filter surface is increased, higher flows are possible, the filter last longer, and the dirt holding capacity increases. Cartridge filters are normally designed disposable: this means that they have to be replaced when the filter is clogged.

\section{Electrostatic precipitators (ESP)}

Electrostatic precipitators operate by charging and collecting particles in a strong electric field between a central electrode and the wall. Gravity forces the mixture of tar and dust to the bottom of the precipitator where it can be removed.

Only wet ESP can be used to remove tar from a biomass gasifier gas, because tar condensation on dry ESPs precipitation electrode would progressively inhibit particle removal. With ESPs, particle removal efficiencies of more than $99 \%$ are possible for particles as small as $0.05 \mu \mathrm{m}$ (Milne et al.,
1998).

\section{Rotating Particle Separator (RPS)}

This is a technique used to separate small particles from a gas or liquid. The filter consists of a large number of small parallel channels, which rotate around a common axis. The specific shape of the channels is not important. Centrifugal forces drive the solid or liquid particles towards the walls, where the particles stick as a result of the centrifugal force, Van der Waals force, or surface tension. The particles collected and agglomerated on the channel walls are removed periodically by injecting pressurized air at high velocity in reverse flow direction into the channels. This is done by a nozzle moving over the rotating filter element at periodic intervals without disturbing the operation of the RPS. The technique is proven for removal of small particles or droplets, down to $0.1 \mu \mathrm{m}$ from gases at ambient temperature (van Kemenade, 2003).

\section{Cooling towers and venturi scrubbers}

Cooling/scrubbing towers are usually used after cyclones as the first wet scrubbing units. All "heavy tar" components condense there. However, tar droplets and gas/liquid mists are entrained by the gas flow, thus rendering the tar removal rather inefficient. Venturi scrubbers are usually the next step (Milne et al., 1998). A venturi scrubber accelerates the waste gas stream to atomize the scrubbing liquid and improve the gas-liquid contact. In a venturi scrubber, a throat section is built into the duct that forces the gas stream to accelerate as the duct narrows and then expands. As the gas enters the venturi throat, both gas velocity and turbulence increase. Depending upon the scrubber design, the scrubbing liquid is sprayed into the gas stream before the gas encounters the venturi throat, or in the throat, or upwards against the gas 
flow in the throat.

The scrubbing liquid is then atomized into small droplets by the turbulence in the throat and droplet-particle interaction is increased. After the throat section, the mixture decelerates, and further impacts occur causing the droplets to agglomerate. Once the particles have been captured by the liquid, the wetted particulate matter and excess liquid droplets are separated from the gas stream by an entrainment section which usually consists of a cyclonic separator or mist eliminator (Corbitt, 1990). The correct selection and dimensioning of wet gas cleaning systems requires information on the particle size distribution in the gas. There are no reliable sets of tar droplet size distributions from biomass producer gases (Corbitt, 1990).

A major issue with using wet gas cleaning systems is the wastewater generated and this economic effect needs to be taken into consideration when recommending such techniques (Milne et al., 1998).

\section{Thermal cracking of tars}

Thermal processes raise the temperature of the producer gas to the levels that "crack" the heavy aromatic tar species into lighter and less problematic species, such as hydrogen, carbon monoxide and methane. For this process, it is suggested that temperatures exceed 1000to reduce tars effectively (Milne et al., 1998).

\section{Steam reforming}

The addition of steam, over and above that formed from the water and oxygen in the feedstock, has been reported to produce fewer refractory tars, enhance phenol formation, reduce the concentration of other oxygenates, have only a small effect on the conversion of aromatics, and produce tars that are easier to reform catalytically (Milne et al., 1998).

\section{Partial oxidation}

Oxygen or air added to steam seems to produce more refractory tars but, while enhancing the conversion of primary tars. When oxygen is added selectively to different stages, such as in secondary zones of a pyrolysis-cracker reactor, tars can be preferentially oxidized (Milne et al., 1998).

\section{Catalytic cracking of tars}

The research on catalytic, hot-gas cleanup has involved (a) incorporating or mixing the catalyst with the feed biomass to achieve socalled catalytic gasification or pyrolysis; and (b) treatment of gasifier raw gas in a second bed or beds. Two main classes of catalyst have been studied: non-metallic and metallic oxides. The most widely used non-metallic catalysts are calcined dolomites and magnesites, zeolites, and olivine (Dayton, 2002). Metallic oxides used as catalyst are generally Nickel based catalysts because they have proved to be efficient for tars and ammonia decomposition in laboratory-scale gas purification experiments (Hepola, 1993). Other transition metals such as Cobalt and Molybdenum may be used as well (Milne et al., 1998).

Although dolomite is the most widely used catalyst and has been proven to be a very effective bed additive in terms of tar reduction, it has some critical limitations. Dolomite is softer and thus gets eroded by the silica sand particles. Also, some dolomite particles break during the calcinations and result in a large production of fines leading to increased carryover of solids from the bed. Dolomite is a calcium magnesium ore with the general chemical formula $\mathrm{CaMg}\left(\mathrm{CO}_{3}\right)_{2}$ that contains approximately $20 \% \mathrm{MgO}, 30 \%$ $\mathrm{CaO}$, and $45 \%$ COon a weight basis (Dayton, 
2002).The use of calcined dolomites in biomass gasification for tar cracking and removal has been the subject of interest in hot gas cleaning. Delgado et al., (1996) studied the use of calcined dolomites in biomass gasification with steam.

The catalytic decomposition of biomass tars using calcined dolomites was also reported by Devi et al., (2005). Calcination of dolomite involves decomposition of the carbonate mineral, eliminating $\mathrm{CO}_{2}$ to form $\mathrm{MgO}-\mathrm{CaO}$. Complete dolomite calcination occurs at fairly high temperatures and is usually performed at $800-900^{\circ} \mathrm{C}$ (Dayton, 2002) and restricts its effective use to these relatively high temperatures. Aznar et al., (1997) performed experiments involving a bed of calcined dolomite placed after a biomass fluidized bed gasifier in which gasification was made with steam-oxygen mixtures to clean the raw syngas. The dolomite was calcined for 2 hours at $900^{\circ} \mathrm{C}$ in an external oven and weighed before its introduction into the reactor. The temperature of the catalytic bed reactor was measured at both the center and at its wall. Experimental results showed a tar elimination of $90-95 \%$ with space time of $0.06-0.15 \mathrm{~kg}$ calcined dolomite $\mathrm{h}^{-1}$ and an increase in the gas yield by $0.15-0.40 \mathrm{~m}^{3}$ at standard temperature and pressure(STP) per kg dry, ash free (daf) biomass fed (Aznar et al., 1997).

An alternative of dolomite can be naturally occurring particles of olivine which is a mineral containing magnesium, iron oxide and silica. Rapagna et al., (2000) have found the tar reforming activity of Olivine comparable to calcined dolomite. Olivine is advantageous in terms of its ability to withstand friction and does not easily break (Devi et al., 2005). However, there is still ambiguity on the prospective use of olivine as a tar decomposing catalyst. It is not yet well known how tars behave in the presence of olivine and hence more attention should be given to find out whether olivine could produce a clean gas with very low tar content (Devi et al., 2005).

Nickel based catalysts have been found to almost completely remove the tar and are also very effective for $\mathrm{NH}_{3}$ removal at temperatures above $800^{\circ} \mathrm{C}$ (Wang et al., 1999). The main limitation of using Nickel based catalysts is severe deactivation of the catalyst. This deactivation occurs mainly when the catalyst is placed right after the gasifier; the high tar concentration has a devastating effect on catalyst activity. More recent work has included dual systems with catalysts such as dolomite serving as a guard bed for highly active catalysts such as Nickel based reforming catalysts. Catalytic processes can operate at much lower temperatures (600$800^{\circ} \mathrm{C}$ ) processes, alleviating the need for expensive alloys for reactor construction (Zhang et al., 2003). Also, unlike physical processes, catalytic cleaning converts the tar, eliminating waste disposal problems. Potentially, catalytic cracking processes provide the simplest and most effective means of removing tars while retaining the sensible heat required for efficient use of the producer gas in close coupled applications. The use of a catalytic reactor downstream of the gasification reactor has proven to be a more effective approach to tar destruction (Kurkela et al., 1993). In using catalysts as gas cleaning technique, there is almost no difference in the lower heating value of the gas produced as the increase in the hydrogen production is compensated by a decrease in carbon monoxide, and there is hardly any change in methane production (Corella et al., 1999).

Gasification of woodchips and pine pellets at atmospheric pressure showed that it was possible to produce a combustible gas from a $\mathrm{t}$ gasifier. The syngas composition and an estimation of the resulting heating value were 
presented. Tars and particulates analysis and control is experimentally had to test with dolomite, Albemarle proprietary catalysts, and bag-filter. The dolomite was treated to varying temperatures. The proprietary catalyst was to be treated with various temperatures. Finally find out the suitable gas cleaning system with less cost.

\section{References}

Antal, M.J., Varhegyi, G. (1995). "Cellulose pyrolysis kinetics: the current state of knowledge," Ind. Eng. Chem. Res. 34, 703-717.

Aznar, M. P., Corella, J., Gil, J., Martin, J. A., Caballero, M. A., Olivares, A., Pérez, P., Francés, E. (1997). "Biomass gasification with steam and oxygen mixtures at pilot scale and with catalytic gas upgrading. Part I: performance of the gasifier." from Developments in Thermochemical Biomass Conversion, Vol. 2, Eds: Bridgwater, A. V., Boocock, D. G. B., Blackie, London, UK, 1194-1208.

Beenackers, A.A.C.M., Maniatis, K. (1996). "Gasification Technologies for Heat and Power from Biomass."

Beenackers, A.A.C.M., Van Swaaij, W.P.M. (1984). "Gasification of Biomass, a State of the Art Review," in Thermochemical Processing of Biomass, Bridgwater, A.V., Ed., London, UK: Butterworths, pp. 91-136.

BTG (Biomass Energy Technologies) (1987). "Thermochemical Conversion of Biomass to Energy." Prepared for UNIDO, Vienna, Austria.

Bui T., Loof R., Bhattacharya S.C. (1994). "Multi-stage reactor for thermal gasification of wood. Energy; 19(4):397-404.

Corbitt, R.A. (1990). "Standard Handbook of Environmental Engineering." McGrawHill Publishing Co., New York.
Corella, J., Aznar, M.P., Gil J., Caballero, M.A. (1999). "Biomass Gasification in Fluidized Bed: Where To Locate The Dolomite To Improve Gasification" Energy and Fuels; 13:1122-7.

Dayton, D. (2002). "A Review of the Literature on Catalytic Biomass Tar Destruction" NREL Technical Report (NREL/TP-510-32815).

De Bari, I., Barisano, D., Cardinale, M., Matera, D., Nanna, F., Viggiano, D. (1999). "Air Gasification of Biomass in a Downdraft Fixed Bed: A Comparative Study of the Inorganic and Organic Products Distribution." Energy and Fuels; 14: 889-898.

Delgado, J., Aznar, M. P., Corella, J. (1996). "Calcined Dolomite, Magnesite, and Calcite for Cleaning Hot Gas from a Fluidized Bed Biomass Gasifier with Steam: Life and Usefulness." Industrial \& Engineering Chemistry Research 35(10), 3637-3643.

Devi, L., Ptasinski, K.J., Janssen, F.J.J.G. (2003). "A Review of the Primary Measures for Tar Elimination in Biomass Gasification Processes."

Devi, L., Ptasinski, K.J., Janssen, F.J.J.G., van Paasen, S.V.B., Bergman P.C.A., Kiel, J.H.A. (2005). "Catalytic Decomposition of Biomass Tars: Use of Dolomite and Untreated Olivine."

Fredriksson, C. (1999). "Exploratory Experimental and Theoretical Studies of Cyclone Gasification of Wood Powder." PhD Dissertation, ISSN: 1402-1544. Department of Mechanical Engineering, Lulea University of Technology, Lulea, Sweden.

Global Air Filtration Systems Inc. http://clean-airquality.com/_wsn/page5. html

Hasler, P., Nussbaumer, T. (1999). "Gas Cleaning for IC Engine Applications from Fixed Bed Biomass Gasification."

Heepola, J. (1993). "Usability of Catalytic 
Gas Cleaning in a Simplified IGCC Power System," Deactivation of $\mathrm{Ni} / \mathrm{A} 12 \mathrm{O} 3$ catalysts. Literature review, Finland. VTT Publication 1445. Hindsgaul, C. (2000). "Low Temperature Particle Filtration of Producer Gas with Low Tar Content."

Heesch, E.J.M., A.J. Pemen, M. Keping, S.V.B Yan, S.V.B. Paasen, and K.J. Ptasinski. (1999). Experimental program of the pulsed corona tar cracker. In: Proc. 12th IEEE Int Pulsed Power Conf. IEEE, New York.

Hindsgaul, C., Schramm, J., Gratz, L., Henriksen, U., Bentzen, J. D. (1999). "Physical and Chemical Characterization of Particles in Producer Gas from Woodchips."

Hos, J.J., Groeneveld, M.J. (1987). "Biomass Gasification." In Biomass, Hall, D.O., Overend, R.P.,eds. Chichester, UK: John Wiley \& Sons, pp.237-255.

Kinoshita C.M., Wang Y., Zhou J. (1994). "Tar formation under different biomass gasification conditions." Journal of Analytical and Applied Pyrolysis; 29:169-81.

Knight R.A. (2000). "Experience with raw gas analysis from pressurized gasification of biomass."Biomass and Bioenergy; 18:67-77.

Kurkela, E., Stahlberg, J., Laatikainan, J., Simell, P. (1993). "Development of Simplified IGCC Processes for Biofuels: Supporting Gasification Research at VTT." Biores Tech., 46:3747.

Maniatis, K. (2001). "Progress in biomass gasification: An Overview." Directorate General for Energy and Transport, European Commission, Brussels, Belgium.

Maxwell T.T., Nevill J.D., Ertas A., Craig J. (2005). "Biomass Feed System Flow Control Using a Weigh Table." Journal of Energy Resources Technology.
Menardi (2003). Menardi Bagouse Types: Pulse Jet. Accessed on 3/03/2008. http://www.menardifilters.com/pulse_je t.htm.

Milne, T. A., Abatzoglou, N., Evans, R.J. (1998). "Biomass gasifier „Tars": Their nature, Formation and Conversion." NREL Technical Report (NREL/TP570-25357).

Mudge, L. K., Baker, E. G., Brown, M. D., Wilcox, W.A. (1987). "Catalysts for Gasification of Biomass." Energy, Biomass, and Wastes 10 1639-1640.

Mudge, L. K., Baker, E. G., Brown, M. D., Wilcox, W.A. (1988). "Catalytic destruction of tars in biomass-derived gases." From Research in Thermochemical Biomass Conversion (Conference), Eds: Bridgewater, A.V., Kuester, J. L., Elsevier Science, Oxford, UK, 1141-1155.

Mukunda, H.S., Paul, P.J., Dasappa, S., Shrinivasa, U., Sharan, H., Buehler, R., Hasler, P., Kaufmann, H. (1994). "Results of an Indo-Swiss Programme for Qualification and Testing of a 300kW IISc-Dasag Gasifier." Energy for Sustainable Development 1 (4), pp. 4649.

New York.50Swaay, W. P. M. van, F. G. van dee Aarsen, A.V. Bridgwater, and A. B. M. Heesink. (1994). "AReview of Biomass Gasification, A report to the European Community." DGXII JOULE program.

Quaak P., Knoef H., Stassen H. (1999). "Energy from Biomass-A Review of Combustion and Gasification Technologies." World Bank Technical Paper No 422-Energy Series. Rapagna, S., Jand, N., Kiennemann, A., Foscolo, P. U. (2000). "Steam-gasification of biomass in ammfluidised-bed of olivine particles." Biomass and Bioenergy 19(3), 187-197.

Raveendran, K., Ganesh, A., Khilar, K.C. 
(1995). "Influence of mineral matter on biomass pyrolysis characteristics," Fuel 74(5), 631-653.Raveendran, K., Ganesh, A., Khilar, K.C. (1996). "Pyrolysis characteristics of biomass and biomass components," Fuel 75(8), 987-998.

Richards, G.N., Zheng, G. (1991). "Influence of metal ions and of salts on products from pyrolysis of wood: applications to thermochemical processing of newsprint biomass," J. Anal. Appl. Pyrolysis 21, 133-146.

Schafer, M. (1999). "Sorptionsverhalten Halogenierter Kohlenwasserstoffe an Aktivkohlen" (Sorption Behavior of Halogenated Hydrocarbons on Activated Carbons). PhD Thesis, University Essen, Essen.mSeinfeld, J.H. (1975). "Air Pollution: Physical and Chemical Fundamentals." McGraw Hill, Inc.USA.

Stassen HEM. (1993). Strategies for upgrading producer gas from fixed bed gasifier systems to internal combustion engine quality. In: graham RG, Bain R, editors. Biomass gasification: hot-gas clean-up. IEA Biomass Gasification Working Group. Pp33-44. Sutton, D., Keller, B., Ross, J. R. H. (2001). "Review of literature on biomass gasification." Fuel Processing Technology 73(3), 155-173.

Svarovsky, L. (1984). "Hydrocyclones."
Technomic Publishing Co., Inc.

Tatsiopoulos, I., Tolis A. (2003). "Economic aspects of the cotton-stalk biomass logistics and comparison of supply chain methods." Biomass Bioenergy 23: 199-214.

Turare, C. (1997). "Biomass Gasification Technology and Utilization." Artes Institute, Universityof Flensburg, Germany.

Van Kemenade, H.P., Mondt, E., Hendriks, A.J.A.M., Verbeek, P.H.J. (2003). "Liquid-Phase

Separation with the Rotational Particle Separator." Chem. Eng. Techn. 26(11), 1176-1183.

Wang, W., Padban, N., Ye, Z., Andersson. A., Bjerle, I. (1999). "Kinetics of Ammonia Decomposition in Hot Gas Cleaning." Industrial and Engineering Chemistry Research; 38:4175-82.

Warnecke, R. (2000). "Gasification of biomass: comparison of fixed-bed and fluidized-bed gasifier." Biomass Bioenergy 18: 489-497.

Wei, L. (2005). "Experimental study on the effects of operational parameters of a downdraft gasifier."

Zhang, R., Brown, R.C., Suby, A., Cummer, K. (2003). "Catalytic Destruction of Tar in Biomass Derived Producer Gas." Energy Conversion and Management 45:995-1014.

\section{How to cite this article:}

Preetha Devi, R., S. Kamaraj, R. Angeeswaran and Pugalendhi, S. 2017. Tar and Particulate Removal Methods for the Producer Gas Obtained from Biomass Gasification. Int.J.Curr.Microbiol.App.Sci. 6(10): 269-284. doi: https://doi.org/10.20546/ijcmas.2017.610.034 